\title{
BARRIERS IDENTIFICATION FOR IMPLEMENTING COLD CHAIN MANAGEMENT: VEGETABLE EXPORT (YUNNAN-THAILAND)
}

\author{
Hongxiu Lai a, Woramol C. Watanabe ${ }^{b}$ \\ ab Naresuan University, Phitsanulok, Thailand \\ Corresponding email: laihongxiumin@gmail.com
}

\begin{abstract}
The vegetable export trade between Yunnan and Thailand is a significant impetus to the economic development of Yunnan province in China. There is huge capital loss caused every year due to the existing post-harvest loss problem. An efficient Cold Chain Management (CCM) is a potential strategic tool for achieving reduction of post-harvest loss of vegetable. However, there are many barriers hindering its successful implementation. The identification of these barriers is required since it is the first critical step to address them. Therefore, this study aims to identify the barriers to implement CCM on exported vegetable from Yunnan to Thailand. Further, it attempts to identify the most influential barriers. To address the vagueness of human beings' assessment, fuzzy set theory is incorporated with the proposed Decision Making Trial and Evaluation Laboratory (DEMATEL) model. Through a thorough literature review and survey questionnaire with managers who come from 13 Yunnan vegetable export companies, 10 barriers have been identified. The result of this study reveals that "lack of government policy and regulatory support", "high cost for installation and operation" and "lack of cold chain industry standard" are the most influential barriers.
\end{abstract}

Keywords: Barriers, Cold Chain Management, Fuzzy DEMATEL, Vegetable Export, Yunnan-Thailand.

\section{Introduction}

The vegetable export trade between Yunnan and Thailand is a significant impetus to the economic development of Yunnan province in China because it has created a high export volume and brought a great deal of revenue to the province. In 2016, the export volume of vegetable reached 8.9 hundred thousand tons with total turnover of 11.5 hundred million dollars ( $\mathrm{Wu}, 2017)$. Thailand is one of the major overseas markets of Yunnan vegetable. But, there are massive capital losses caused on every year due to the existing post-harvest loss problem. Post-harvest losses of vegetable in export trade would not only reduce profitability to company directly and hinder the development of vegetable export trade, but also reduce the accessibility of vegetable to consumers with an increased sense of competition, more and more exporters look forward to achieving the reduction of post-harvest losses. 
Because vegetable is perishable and difficult to save, these characteristics set even higher demands in the post-harvest chain and marketing section (Liu, 2015). An efficient Cold Chain Management (CCM) is a potential strategic tool for maintaining the quality of perishable products like the vegetable (Joshi, Banwet, \& Shankar, 2009). Cold chain is defined as the special supply chain and distribution chain for products that must be kept within a specific temperature range (Castiaux, 2010). In brief, all activities carried out in an unbroken cold chain are defined as CCM. As an important branch of supply chain management (SCM), CCM has been retrieving much attention over the last few years. The successful implementation of CCM enables a reduction the post-harvest loss, as well as improves the operational efficiency of supply chain (FAO \& IIR, 2016).

However, the concept of CCM is not yet widely popular in Yunnan vegetable export companies that target Thailand market because they face a multitude of barriers for CCM successful implementation. These barriers create severe challenges for the industries and managers. It is necessary to identify these barriers since it is the first critical step to address them. In fact, the development of an organization is often confined by the limited resources which prevent it addressing effectively all the proposed barriers. It is better for an organization to focus on addressing the most influential barriers first. Ranking of barriers bases on their influences may help senior managers accelerate the changes from the present patterns and cultivate the strategy to overcome them. Based on the above statement, identifying and ranking the barriers for CCM implementation in context of exporting vegetable from Yunnan to Thailand are required. Hence, this study aims to identify the barriers to implement CCM on exported vegetable from Yunnan to Thailand. Further, it attempts to identify the most influential barriers. In this study, fuzzy DEMATEL model is presented to rank and identify the most influential barriers for implementing CCM. Decision Making Trial and Evaluation Laboratory (DEMATEL) is one of the powerful techniques to help decision maker for setting up the ranking among multiple criteria. DEMATEL has been extensively applied in many management fields to handle complex problems (Wang \& Zhang, 2010). However, conventional DEMATEL can't address the vagueness and imprecision of human judgments, in order to address this problem, fuzzy set theory is incorporated with DEMATEL in this study.

The remainder of this paper is organized as follows. In section 2, prior works about the barrier identification for implementing CCM and fuzzy DEMATEL technique are reviewed. In section 3, the outline of the methodology of this study is shown. In section 4 , the application of the proposed methodology in Yunnan vegetable export industry is presented. In section 5 , the result and discussion are conducted. Finally, the conclusion is drawn.

\section{Literature Review 2.1CCM Barrier Identification}

CCM is a special SCM that manages vegetable, fruits and other perishable products from the origin after product processing, storage, transportation, distribution, retail and other sector are always suitable for low-temperature controlled circumstance to ensure maximum product quality and safety, reduce losses(Liu, 2015). CCM is a more complicated challenge for exporters. In vegetable export cold chain, the integration of the multiple processes and the high requirement of specific technology are required. Furthermore, cold chain has an 
irreversible characteristic, any break in the cold chain would cause the loss of quality or total loss of products (Freiboth et al, 2013). All of these determine the fact that there are quite a number of barriers hindering the implementation of efficient CCM, which results in concept of CCM is not yet widely accepted.

The existing literature reveals that the barriers for implementing CCM have been broadly investigated. Lack of adequate infrastructure along with high cost for installation and operation, and lack of government policy and regulatory support were often the bottlenecks for vigorous and efficient cold chain (Saurav \& Potti, 2016). In addition, lack of cooperation between significant role players was a key barrier responsible for high food loss in cold chain as well (Jemric \& Ilic, 2012). Lack of industry standards of implementation of CCM, technology can't be applied to many types of food and lacking overall integrated planning were the barriers that hinder the development of $\mathrm{CCM}$ in transit transport and storage in China, Near East and North Africa area (FAO, 2015; Qu, 2015).Besides, lack of capacity in the management and maintenance of cold chain infrastructures were also critical barriers to implement CCM in many developing countries (FAO, 2015). What deserves to be mentioned is that a few researchers have started to turn to study the characteristic of the barriers. For instance, Joshi et al (2010) applied ISM fuzzy-MICMAC model to explore the barriers that influence the efficiency of a cold chain for vegetable and fruit sector in India. Bag (2016) studied the key barriers influencing green cold chain management practices in the agriculture industry of India by utilizing ISM technique. However, the number of these papers is not large. Up to now, though much current research shows that the barriers to implement CCM have been broadly examined, there are still some limitations in this field. The prior literature shows that research on barriers to implement CCM was still not deepened enough and can't provide a clear identification and ranking. In the theoretical section, few of them identified the most influential barriers. In the practical section, few attempts have been made to focus on the barriers for implementing CCM on vegetable exported from Yunnan to Thailand. This study is to fill in this gap.

\subsection{Fuzzy DEMATEL Model}

Fuzzy DEMATEL model is an effective tool for identifying main problem in a complex system involving multiple factors in the fuzzy environment. Fuzzy DEMATEL is integrated by fuzzy logic theory and DEMATEL model. Specifically, DEMATEL model was originally proposed by Fontela and Gabus in 1976 with the purpose of dealing with the intertwined problem. DEMATEL method is based on digraphs, which can categorize involved factors into cause group and effect group (Garg, Luthra, \& Haleem, 2016).It has gained increased attention as it can visualize the structure of complicated causal relationship in system. As an effective multiple criteria decision making tool, DEMATEL has become very popular in the area of SCM during the past years. Wang \& Zhang (2010) proposed DEMATEL to recognize the core issue in SCM. They claimed that the proposed DEMATEL model can turn a complicated system into clear a visual structure and identify core problems and improvement. Zhu et al.,(2014) applied DEMATEL to examine the cause-effect relationships among various implementation barriers from a remanufacturing supply chain perspective. Their research introduced a research framework to identify the key barriers to development remanufacture industry in China. Wang \& Hu (2015) utilized the DEMATEL 
model to rank the influence factors and identify the major factors influencing the fruit and vegetable product cold chain logistics in the big Xiangxi region of China.

Generally, assessments given by human beings are linguistic and vague, which make it difficult to make further analysis and compute. Fuzzy set theory can be utilized to measure the vague concepts associated with human's subjective assessment. Conventional DEMATEL model can neither measure these linguistic concepts nor take the vagueness of variables into account either in decision making process. Therefore, integrating DEMATEL with fuzzy set theory is necessary .Fuzzy set theory was developed based on the concept of membership function and designed to take linguistic variables into consideration under fuzzy circumstance. The fuzzy DEMATEL enables a more accurate description of humans' preference and research result more closely with human thought patterns. Fuzzy DEMATEL has been obtained a wide range of applications in logistics and SCM section, such as evaluation supplier selection criteria (Mavi \& Shahabi, 2015), evaluation the performance of SCM practices (Govindan, Khodaverdi \& Vafadarnikjoo, 2015),identification supplier(Mavi, Kazemi, Najafabadi\&Mousaabadi.,2013) , solving transportation management issue (Parviz, Sadegh \& Zinat 2016) and identification of the barriers to implement reverse logistics (Garg et al., 2016). Nevertheless, there are few studies concentrated on the CCM in the context of vegetable export through the fuzzy DEMATEL methodology.

\section{Methodology}

In this section, 4 steps are proposed to achieve the objectives of this study, as shows in figure1.

\begin{tabular}{|c|}
\hline \multicolumn{2}{|c|}{ Review literature and validate barriers based on managers' opinion } \\
\hline Obtain experts' opinion on degree of influence between pairwise barriers \\
\hline Apply Fuzzy DEMATEL model \\
$\qquad$ \\
\hline Analyze the result based on the cause-effect diagram \\
\hline
\end{tabular}

Figure 1: The outline of methodology

Firstly, review the literature and validate the barriers based on managers' opinions. To acquire managers' validation, a questionnaire was administrated to managers from Yunnan vegetable export companies. After that, the second-time questionnaire was presented to experts in field of CCM to obtain the opinions on degree of influence between pairwise barriers using the 5 linguistic terms as shown in table1. Finally, on the basis of data collected, fuzzy DEMATEL is applied to analyze the result. Fuzzy DEMATE model compose the following steps as described below:

\section{Step1. Convert the Linguistic Terms into Triangular Fuzzy Numbers (TFNs)}

TFNs set is one of fuzzy sets developed based on the fuzzy logic theory. According to experts' assessments, the linguistic terms were converted into corresponding TFNs data sets provided in table 1. 
Table 1: Linguistic terms and TFNs used in present study

\begin{tabular}{cc}
\hline Linguistic Terms & Corresponding TFNs \\
\hline No influence(NO) & $(0,0,0.25)$ \\
Very Low influence(VL) & $(0,0.25,0.5)$ \\
Low influence(L) & $(0.25,0.5,0.75)$ \\
High influence(H) & $(0.5,0.75,1.0)$ \\
Very High influence(VH) & $(0.75,1.0,1.0)$ \\
\hline
\end{tabular}

\section{Step2. Defuzzify TFNs into the Crisp Score}

Since the form of TFNs is not suitable for matrix calculation and aggregation, defuzzication algorithm is needed, which is a process of transforming TFNs into crisp score (CFCS). $z_{i j}^{\mathrm{h}}=\left(l_{i j}^{\mathrm{h}}, m_{i j}^{\mathrm{h}}, r_{\mathrm{i} j}^{\mathrm{h}}\right)$ means fuzzy assessment given by evaluator $\mathrm{h}(\mathrm{h}=1,2,3 \ldots, \mathrm{H})$ about the degree on which the factor $\mathrm{i}$ influences the factor $\mathrm{j}$. The initial direct-relation matrix is acquired in this step. The CFCS method includes the following 5 Phrases.

Phrase 1: Normalization

$$
\begin{aligned}
\mathrm{xl}_{\mathrm{ij}}^{\mathrm{h}} & =\left(\mathrm{l}_{\mathrm{ij}}^{\mathrm{h}}-\operatorname{minl}_{\mathrm{ij}}^{\mathrm{h}}\right) / \Delta_{\min }^{\max }(1) \\
\mathrm{xm}_{\mathrm{ij}}^{\mathrm{h}} & =\left(\mathrm{m}_{\mathrm{ij}}^{\mathrm{h}}-\operatorname{minl}_{\mathrm{ij}}^{\mathrm{h}}\right) / \Delta_{\min }^{\max }(2) \\
\mathrm{xr}_{\mathrm{ij}}^{\mathrm{h}} & =\left(\mathrm{r}_{\mathrm{ij}}^{\mathrm{h}}-\operatorname{minl}_{\mathrm{ij}}^{\mathrm{h}}\right) / \Delta_{\min }^{\max }(3)
\end{aligned}
$$

Phrase 2: Calculate the left and right normalized value

$$
\begin{aligned}
& \mathrm{xls}_{\mathrm{ij}}^{\mathrm{h}}=\mathrm{xm}_{\mathrm{ij}}^{\mathrm{h}} \div\left(1+\mathrm{xm}_{\mathrm{ij}}^{\mathrm{h}}-\mathrm{xl}_{\mathrm{ij}}^{\mathrm{h}}\right)(4) \\
& \mathrm{xrs}_{\mathrm{ij}}^{\mathrm{h}}=\mathrm{xr}_{\mathrm{ij}}^{\mathrm{h}} \div\left(1+\mathrm{xr}_{\mathrm{ij}}^{\mathrm{h}}-\mathrm{xm}_{\mathrm{ij}}^{\mathrm{h}}\right)(5)
\end{aligned}
$$

Phrase 3: Calculate the total normalized value

$$
\mathrm{x}_{\mathrm{ij}}^{\mathrm{h}}=\left[\operatorname{xls}_{\mathrm{ij}}^{\mathrm{h}}\left(1-\mathrm{xls}_{\mathrm{ij}}^{\mathrm{h}}\right)+\mathrm{xrs}_{\mathrm{ij}}^{\mathrm{h}} \times \mathrm{xrs}_{\mathrm{ij}}^{\mathrm{h}}\right] \div\left(1+\mathrm{xrs}_{\mathrm{ij}}^{\mathrm{h}}\right)(6)
$$

Phrase 4: Obtain the crisp score of the $\mathrm{h}^{\text {th }}$ expert's assessment $\mathrm{BNP}_{\mathrm{ij}}^{\mathrm{h}}=\operatorname{minl}_{\mathrm{ij}}^{\mathrm{h}}+\mathrm{x}_{\mathrm{ij}}^{\mathrm{h}} \Delta_{\min }^{\max }(7)$

* BNP indicates Best Non-fuzzy Performance

$$
\mathrm{a}_{\mathrm{ij}}=\frac{1}{\mathrm{H}} \sum_{\mathrm{H}}^{1 \leq \mathrm{h}} \leq \mathrm{H} \mathrm{BNP}_{\mathrm{ij}}^{\mathrm{h}}(8)
$$

Phrase 5: Get integrated scores by averaging the crisp scores of all $\mathrm{H}$ assessment. The initial direct-relation matrix A is acquired in this step.

Step3: Normalize the Initial Direct-Relation Matrix and Calculate the Total Relation Matrix T by Formula:

$$
\begin{aligned}
& \mathrm{S}=\frac{1}{\max _{1 \leq \mathrm{i} \leq \mathrm{n} \sum_{\mathrm{j}=1}^{n} \mathrm{a}_{\mathrm{ij}}}}(9) \\
& \mathrm{M}=\mathrm{A} \times \mathrm{S} \\
& \mathrm{T}=\mathrm{M}(\mathrm{I}-\mathrm{M})^{-1}(11)
\end{aligned}
$$




\section{Step4: Calculate Sum of Rows D and the Sum of Columns R Within the Total-Relation Matrix M Through the Following Formulas:}

$$
\begin{aligned}
& \mathrm{D}=\left(\sum_{\mathrm{j}=1}^{\mathrm{n}} \mathrm{m}_{\mathrm{ij}}\right)_{\mathrm{n} \times 1}(12) \\
& \mathrm{R}=\left(\sum_{\mathrm{i}=1}^{\mathrm{n}} \mathrm{m}_{\mathrm{ij}}\right)_{1 \times \mathrm{n}}(13)
\end{aligned}
$$

The sum of rows D (influential impact) shows total influences that factor (i) has on other factors and sum of columns R (influenced impact) shows total influences of factor (j) receiving from the other factors.

Step5: Draw the cause-effect diagram. In drawing the cause-effect diagram, vertical axis and horizontal axis are made by (D-R, D+R).D+R is known as "prominence", which exhibits the degree of central role that the factor (i) plays in the problematique. (D-R) is known as "relation", which exhibits the degree of cause of the factor. If (D-R) is positive, the factor is grouped into cause group, if (D-R) is negative, the factor is grouped into effect group.

\section{The Application of Proposed Methodology}

This section describes the outcome of applying the proposed methodology.

4.1.10 barriers were identifiedon the basis of a thorough of existing 89 literature and validated with managers from 13 Yunnan vegetable export companies as depicted in table 2.

Table 2: 10 barriers for implementing CCM on exported vegetable from Yunnan to Thailand

\begin{tabular}{lll}
\hline & Barriers & Literature \\
\hline B1 & Lack of skilled human resource & Smith(2005);FAO(2015);Shi(2016) \\
B2 & High cost for installation and operation & Jat(2010);Lan\&Tian(2013);Shi(2016) \\
B3 & Lack of top level commitment & Jayant \& Azhar(2014); Gorane \& Kant(2015) \\
B4 & Lack of the use of information system & Aung \& Chang(2014);Weng, An, \& Yang( 2015) \\
B5 & Lack of implementing standardization & Bharti(2014);FAO(2015);Qu(2015) \\
B6 & Lack of coordination between & FAO(2015);Brison\&Tallec(2017) \\
& stakeholders & \\
B7 & Customer's unawareness towards CCM & Ovca\&Jevsnik(2009);Joshi,Banwet,\& \\
& vegetable & Shankar(2010) \\
B8 & Lack of government policy and regulation & Bharti(2014); FAO(2015); Shi(2016) \\
& support & \\
B9 & Poor cold storage infrastructure & Liu et al(2016); Saurav\&Potti(2016) \\
B10 & Lack of maintenance of infrastructure & FAO \& IIR(2016);Ashok, et al(2017) \\
\hline
\end{tabular}

4.2Obtain experts' opinions on the degree of influence between pairwise barriers. 6 industrial and academic experts who all have a rich knowledge and experience in the field of CCM were asked to conduct pairwise comparison between 10 barriers by using the 5 linguistic terms as provided in table 1.

4.3Result of applying fuzzy DEMATEL are explained as follows: step1, convert the linguistic terms into fuzzy TFNs according to table 1. Step2, defuzzify TFNs into crisp score through formulas (1)-(7). After that average crisp scores of 6 experts' assessment to get the initial direct-relation matrix by utilizing formula (8), as presented in table 3. Step3, normalize initial direct-relation matrix through formulas (9) - (10). Step4, use formulas (11)-(13) to calculate the total relation matrix, prominence and relation, which are shown in table 4 and table 5 respectively. Only the degree of influence that are over the threshold value $\theta$ (0.35) were shown in bold in total relation matrix. The threshold acquires from the sum of mean 
(0.273) and standard deviation (0.077) of the scores from total matrix. Step5, draw the cause-effect diagram by mapping the data set of the (D + R, D - R) as shown in Fig 2.

Table 3: The initial direct-relation matrix

\begin{tabular}{ccccccccccc}
\hline & B1 & B2 & B3 & B4 & B5 & B6 & B7 & B8 & B9 & B10 \\
\hline B1 & 0.000 & 0.303 & 0.342 & 0.458 & 0.653 & 0.147 & 0.303 & 0.108 & 0.263 & 0.302 \\
B2 & 0.263 & 0.000 & 0.382 & 0.538 & 0.693 & 0.265 & 0.537 & 0.420 & 0.773 & 0.617 \\
B3 & 0.812 & 0.187 & 0.000 & 0.693 & 0.538 & 0.263 & 0.147 & 0.382 & 0.458 & 0.537 \\
B4 & 0.303 & 0.460 & 0.420 & 0.000 & 0.615 & 0.458 & 0.380 & 0.225 & 0.382 & 0.302 \\
B5 & 0.458 & 0.537 & 0.497 & 0.773 & 0.000 & 0.458 & 0.460 & 0.382 & 0.695 & 0.617 \\
B6 & 0.030 & 0.420 & 0.223 & 0.380 & 0.420 & 0.000 & 0.303 & 0.187 & 0.380 & 0.147 \\
B7 & 0.225 & 0.107 & 0.535 & 0.577 & 0.498 & 0.263 & 0.000 & 0.458 & 0.613 & 0.458 \\
B8 & 0.460 & 0.458 & 0.695 & 0.695 & 0.772 & 0.617 & 0.420 & 0.000 & 0.693 & 0.577 \\
B9 & 0.302 & 0.380 & 0.497 & 0.458 & 0.537 & 0.342 & 0.537 & 0.458 & 0.000 & 0.418 \\
B10 & 0.497 & 0.460 & 0.420 & 0.460 & 0.693 & 0.380 & 0.497 & 0.380 & 0.342 & 0.000 \\
\hline
\end{tabular}

Table 5: Total relation matrix

\begin{tabular}{ccccccccccc}
\hline & B1 & B2 & B3 & B4 & B5 & B6 & B7 & B8 & B9 & B10 \\
\hline B1 & 0.136 & 0.186 & 0.215 & 0.274 & 0.312 & 0.155 & 0.195 & 0.141 & 0.224 & 0.210 \\
B2 & 0.253 & 0.203 & 0.306 & $\mathbf{0 . 3 8 6}$ & $\mathbf{0 . 4 2 6}$ & 0.243 & 0.309 & 0.258 & $\mathbf{0 . 3 9 9}$ & 0.343 \\
B3 & 0.316 & 0.212 & 0.206 & 0.371 & 0.363 & 0.216 & 0.215 & 0.220 & 0.307 & 0.295 \\
B4 & 0.213 & 0.238 & 0.257 & 0.233 & 0.345 & 0.231 & 0.235 & 0.185 & 0.278 & 0.240 \\
B5 & 0.293 & 0.304 & 0.334 & $\mathbf{0 . 4 3 6}$ & 0.328 & 0.283 & 0.306 & 0.258 & $\mathbf{0 . 3 9 6}$ & $\mathbf{0 . 3 5 1}$ \\
B6 & 0.123 & 0.188 & 0.176 & 0.235 & 0.248 & 0.112 & 0.178 & 0.140 & 0.222 & 0.164 \\
B7 & 0.216 & 0.192 & 0.292 & 0.345 & 0.344 & 0.213 & 0.180 & 0.233 & 0.327 & 0.277 \\
B8 & 0.317 & 0.314 & $\mathbf{0 . 3 9 0}$ & $\mathbf{0 . 4 5 7}$ & $\mathbf{0 . 4 8 5}$ & 0.330 & 0.321 & 0.212 & $\mathbf{0 . 4 2 5}$ & $\mathbf{0 . 3 7 0}$ \\
B9 & 0.235 & 0.242 & 0.295 & 0.339 & $\mathbf{0 . 3 6 3}$ & 0.231 & 0.280 & 0.240 & 0.238 & 0.281 \\
B10 & 0.272 & 0.263 & 0.288 & 0.349 & $\mathbf{0 . 3 9 8}$ & 0.242 & 0.281 & 0.232 & 0.306 & 0.217 \\
\hline
\end{tabular}

Table 6: The prominence and relation

\begin{tabular}{ccccccc}
\hline & $\mathrm{D}$ & $\mathrm{R}$ & $\mathrm{D}+\mathrm{R}$ (prominence) & Rank & D-R(Relation) & Rank \\
\hline B1 & 2.047 & 2.374 & 4.421 & 9 & -0.327 & 7 \\
B2 & 3.125 & 2.342 & 5.467 & 7 & 0.783 & 2 \\
B3 & 2.721 & 2.758 & 5.479 & 6 & -0.037 & 5 \\
B4 & 2.454 & 3.425 & 5.879 & 2 & -0.971 & 10 \\
B5 & 3.289 & 3.611 & 6.9 & 1 & -0.322 & 6 \\
B6 & 1.786 & 2.256 & 4.042 & 10 & -0.47 & 9 \\
B7 & 2.619 & 2.498 & 5.117 & 8 & 0.121 & 3 \\
B8 & 3.620 & 2.117 & 5.737 & 4 & 1.503 & 1 \\
B9 & 2.743 & 3.121 & 5.864 & 3 & -0.378 & 8 \\
B10 & 2.847 & 2.748 & 5.595 & 5 & 0.099 & 4 \\
\hline
\end{tabular}




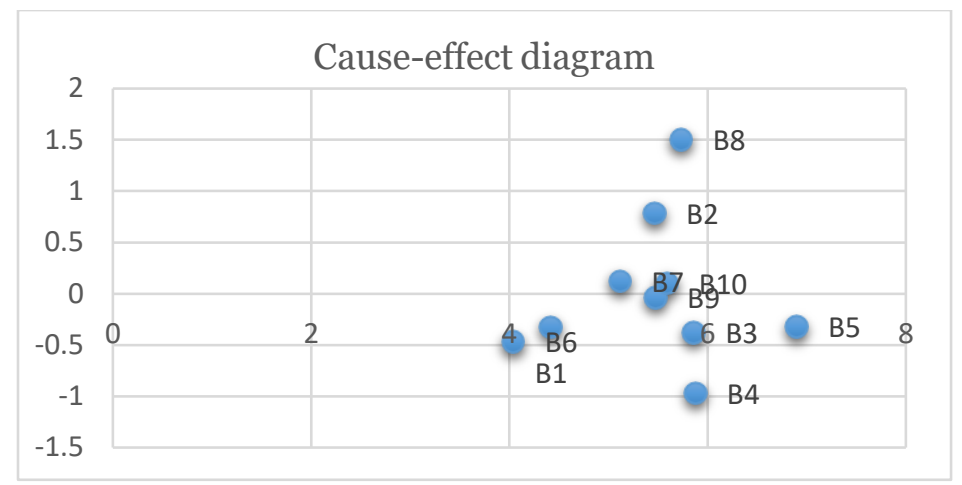

Figure2: The cause-effect diagram

\section{Result and Discussion}

This figure portrays a clear visualization of the interrelationships among the 10 barriers. This cause-effect diagram reveals that six barriers, namely, B3, B5, B1, B1, B4 and B6 are categorized into effect group which tend to be easily influenced by other barriers. This is because their (D-R) scores are negative indicating the influential impact (D) of these barriers are lower than their influenced impact (R). In addition, it shows that B2, B7, B8, B10 are categorized into cause group. The barriers in cause group have more influential impact (D) than influenced impact (R), which tend to influence other barriers in system.

It is necessary to focus on the cause group factor due to their influence on the effect group factor (Fontela \& Gabus, 1976). Figure2 shows B8 is the most influential barriers because in ranking of relation (net effect) score, B8 got the highest score (1.503). Hence, B8 can be taken into consideration as the most influential barrier. Similarly, barrier B2 possesses relation score (D-R) is as high as 0.783 (seen in table 6), which ranks second place among the cause group. Consequently, B2 can be selected as one of the most influential barriers. Although B7 and B10 are in cause group, their relation score is very low. Hence, B7 and B10 can't be defined as the most influential barriers to implement CCM on exported vegetable from Yunnan to Thailand.

Prominence score presents the degree of central role that the barrier plays in the problematique. Barrier $\mathrm{B}_{5}$ got the highest prominence score of 6.9, and its D score and $\mathrm{R}$ score which are 3.289 and 3.611, respectively are both very high among other barriers, so it should be considered as a relatively influential barrier and critical one for the implementation of CCM.B9 and B10 rank after B5 in the prominence ranking. With regards to B9, though it ranks second in ranking of prominence, its influential impact is negative and it is defined as effect barrier. B9 is not considered as the critical barrier.

Overall, both relation and prominence should be given fully consideration. Therefore, the result of this study reveals that "lack of government policy and regulatory support"(B8), "high cost for installation and operation"(B2) and "lack of implementing standardization" (B5) are identified as the most influential barriers for the implementation of CCM on exported vegetable from Yunnan to Thailand. Thus, priority and attention should be given to above 3 barriers. This result was compatible with research result of Bag (2016) where "lack of government policy and regulatory support" was recognized as the barriers with the high influence and strong drive power to implement cold chain management. Government support is critical for lower the high cost, facilitation of the top level commitment of the company and the use of information system, as well improvement the cold storage infrastructure(see from total relation matrix). In this regard, government's vital role is inevitable. Briefly put, the government should take a great role in supporting Yunnan vegetable export industry players in their initiative and provide a more conductive environment. This study also confirms to the Joshi et al. (2009) which observed that barrier "high cost for installation and operation" was the biggest bottleneck for efficient CCM. The achievement of reducing cost is extremely 
significant to the implementation of CCM. Last but not least, the cold chain industry implementing standardization is also essential to the development of CCM in industry. It is suggested that relative stakeholders should accelerate build and execute the industrial CCM implementation standard such as the HACCP (Hazard Analysis and Critical Control Points), GAP (Good Agricultural Practices), GMP (Good Manufacturing Practice), ISO (International Organization for Standardization) and so on.

\section{Conclusion}

A successful CCM implementation requires identification of the existing barriers. The identification of barriers for implementing CCM on exported vegetable from Yunnan to Thailand was conducted in this study. 10 barriers were identified on the basis of thorough existing literature review and managers' opinions. Fuzzy DEMATEL model was utilized to rank the barriers and identify the most influential barriers. Among which, fuzzy set theory was applied to address the vagueness and imprecision of experts' assessment. The result of this research indicated that "lack of government policy and regulatory support", "high cost for installation and operation" and "lack of implementing standardization" were the most influential barriers to implement CCM on exported vegetable from Yunnan to Thailand. This study facilitatesa better understanding of the barriers for implementing CCM and it would offer the managers or relative organizations with a number of valuable managerial implications as well.

What should be noted is that this study is limited to the sample size of the company used which may limit the generalizability of current findings. It can achieve more comprehensive investigation if there are more involvement of the companies in future study. 


\section{Reference}

i. A.Bharti, 2014. Examining Market Challenges Pertaining to Cold Chain in the Frozen Food Industry in Indian Retail Sector. Journal of Management Sciences And Technology, 2(1), p. $33-40$.

ii. Ashok, A., Brison, M. \& LeTallec, Y., 2017. Improving Cold Chain Systems: Challenges and Solutions. Vaccine, 35(17), p. 2217-2223.

iii. Aung, M. \& Chang, Y., 2014. Temperature Management for the Quality Assurance of Perishable Food supply chain. Food Control, Volume 40, p. 198-207.

iv. Bag, S., 2016. Modeling Barriers of Green Cold Chain Management in India. Journal of Supply Chain Management Systems, 5(1), pp. 37-45.

v. Brison, M. \& Tallec, Y., 2017. Transforming Cold Chain Performance and Management in Lower-income Countries. Vaccine, 35(17), pp. 2107-2109.

vi. Castiaux, E., 2010. An Introduction to Cold Chain Management. Journal of GXP Compliance, 14(4), p. 19-22.

vii. FAO ; IIR, 2016. Report Developing the Cold Chain in the Agrifood Sector in Sub-Saharan Africa. Food and Agriculture Organization of the United Nations, pp. 1-4.

viii. FAO, 2015. Developing the Cold Chain for Agriculture in the Near East and North Africa (NENA). Food and Agriculture Organization of the United Nations Policy Brief, pp. 1-4.

ix. Fontela, E. \& Gabus, A., 1976. The DEMATEL Observer, Switzerland, Geneva: Battelle Geneva Research Center.

x. Freiboth, H., Goedhals-Gerber, L., Dyk, F. V. \& Dodd, M., 2013. Investigating Temperature Breaks in the Summer Fruit Export Cold Chain. Journal ofTransport and Supply Chain Management, 7(1), pp. 1-7.

xi. Garg, D., Luthra, S. \& Haleem, A., 2016. An Evaluation of Barriers to Implement Reverse Logistics: A Case Study of Indian Fastener Industry. International Journal of Mechanical Aerospace, Industrial, Mechatronic and Manufacturing Engineering, 10(8), p. 1436-1441.

xii. Gharakhani, D., 2012. The Evaluation of Supplier Selection Criteria by Fuzzy DEMATEL Method. Journal of Basic and Applied Scientific Research, 2(4), p. 3215-3224.

xiii. Gorane, S. \& Kant, R., 2015. Modelling the SCM Implementation Barriers. Journal of Modelling in Management, 10(2), p. 158-178. 
xiv. Govindan, K., Khodaverdi, R. \& Vafadarnikjoo, A., 2015. Intuitionistic Fuzzy Based DEMATEL Method for Developing Green Practices and Performances in a Green Supply Chain. Expert Systems with Applications, 42(20), p. 7207-7220.

xv. Jat, S., 2010. Technology on Reducing Post-harvest Losses and Maintaining Quality of Fruits and Vegetables in India. Proceeding of 2O1O AARDO Workshop, pp. 114-124.

xvi. Jayant, A. \& Azhar, M., 2014. Analysis of the Barriers for Implementing Green Supply Chain Management (GSCM) Practices: An Interpretive Structural Modeling (ISM) Approach. Proceeding of 12th Global Congress on Manufacturing and Management Conference, 97(2014), p. 2157-2166.

xvii. Jemric, T. \& Z.Ilic, 2012. Present State of Cold Chain and Postharvest Loss of Fruits and Vegetables in Croatia and Serbia. Agriculturae Conspectus Scientificus, 77(1), pp. 1-4.

xviii. Joshi, R., Banwet, D. \& Shankar, R., 2009. Indian Cold Chain: Modeling the Inhibitors. British Food Journal, 111(11), p. 1260-1283.

xix. Lan, H. \& Tian, Y., 2013. Analysis of the Demand Status and Forecast of Food Cold Chain in Beijing. Journal of Industrial Engineering and Management, 6(1), p. 346-355.

xx. Lin, R., 2013. Using fuzzy DEMTEL to Evaluate the Green Supply Chain Management Practices. Journal of Cleaner Production, Volume 40, p. 32-39.

xxi. Liu, X., M.Xu \& C.Yu, 2016. Food Cold Chain Logistics Based on Internet of Things Technology Proceeding of the 2016 6th International Conference on Applied Science, Engineering and Technology, Changchun: Jilin Agricultural University.

xxii. Li, Y. et al., 2016. A Feasibility Research on the Mechanism of Cold Chain Business in Deppon Logistics. International Journal of $U$ - and E - Service Science and Technology, 9(3), p. 157-168.

xxiii. Mavi, R., S.Kazemi, Najafabadi, A. \& Mousaabadi, H. B., 2013. Identification and Assessment of Logistical Factors to Evaluate a Green Supplier Using the Fuzzy Logic DEMATEL Method. Polish Journal of Environmental Studies, 22(2), p. 445-455.

xxiv. Mavi, R. \& Shahabi, H., 2015. Using Fuzzy DEMATEL for Evaluating Supplier Selection Criteria in Manufacturing Industries. International Journal of Logistics Systems and Management, 22(1), pp. $15-45$.

xxv. Mehregan, M., Hashemi, S., A.Karimi \& Merikhi, B., 2014. Analysis of Interactions among Sustainability Supplier Selection Criteria Using ISM and Fuzzy DEMATEL. International Journal of Applied Decision Sciences, 7(3), p. 270-294.

Ovca, A. \& M.Jevsnik, 2009. Maintaining a Cold Chain from Purchase to the Home and at Home. 
Consumer Opinions. Food Control, 20(2), p. 167-172.

xxvii. Parviz, B., Sadegh, J. \& J.Zinat, 2016. Application of Fuzzy DEMATEL Model to Identify and Analyze the Relationship between Factors Affecting Port Privatization in Iran. Journal of Oceanography, 7(25), p. 23-31.

xxviii. Q.Zhu, J.Sarkis \& K.Lai, 2014. Supply Chain Based Barriers for Truck-engine remanufacturing in China. Transportation Research Part E. Logistics and Transportation Review, Volume 68, p. $103-117$.

xxix. Saurav, S. \& Potti, R., 2016. Innovative Solutions for Implementing Global Supply Chains in Emerging Markets- Cold Chain Logistics in India, Hershey, Pa: IGI Global.

xxx. Shashi, Rajwinder, Singh, R. \& A.Shabani, 2016. The Identification of Key Success Factors in Sustainable Cold Chain Management: Insights from the Indian Food Industry. Journal of Operations and Supply Chain Management, 9(2), pp. 1-16.

xxxi. Smith, J., 2005. Specialized Logistics for A Longer Perishable Supply Chain. World Trade, Volume 18 , p. $46-48$.

xxxii. Wang, Xiao-yan \& Zhang, J., 2010. Research on Management Complexity in Supply Chain Problems Based on DEMATEL Proceeding of 2010 International Conference on Management and Service Science, Heibei, China: Wuhan University.

xxxiii. Wang, Z. \& Hu, L., 2015. Evaluation of Influence Factors on Fruit and Vegetable Products Cold Chain Logistics in Big Xiangxi Region. Logistics Technology Journal, Volume 4, pp. 136-138.

xxxiv. Weng, X., An, J., Yang \& Hui, 2015. The Analysis of the Development Situation and Trend of the City -oriented Cold Chain Logistics System for Fresh Agricultural Products. Open Journal of Social Sciences, 3(1), p. 470-480.

xxxv. Wu, P., 2017. Yunnan Agricultural Products for Exporting in 2016-Fruit Ranking First Report of Yunnan. [Online] Available at: www.yunnan.cn.

xxxvi. Y.Qu, 2015. Research on Fresh Produce Food Cold Chain Logistics Tracking System Based on RFID. Advance Journal of Food Science and Technology, 7(3), p. 191-194.

xxxvii. Z.Liu, 2015. Research on the Performance Evaluation Method for Cold Chain Logistics of Agriculture Products Based on BP Neural Network Mode. The Open Cybernetics \& Systemics Journal, Volume 9, p. 2168-2172. 